\title{
Use of Film to Sensitize Medical Students to Issues of Family Caregiving
}

Kristin R. Baughman, PhD | Barbara Palmisano, MA | Margaret Sanders, MA, LSW | Michael Blackie, PhD | David Sperling, MD | Erin Scott, MD | Steven Radwany, MD | Jennifer Drost, DO, $\mathrm{MPH}$

PRIMER. 2019;3:14.

Published: 4/11/2019 | DOI: 10.22454/PRiMER.2019.254302

\section{Abstract}

Background and Objective: Families are the backbone of our long-term care system, managing complicated illnesses, providing direct care, and assisting with the day-to-day functioning of elderly patients. Medical education, however, provides students with little, if any, exposure to the challenges faced by family caregivers or how best to communicate with them to optimize patient care. We assessed the value of an educational program combining film and discussion as a means of sensitizing third-year medical students to caregiver issues. During their family medicine clerkship, third-year medical students at Northeast Ohio Medical University view the film, No Roadmap: Caregiver Journeys and discuss issues of family caregiving.

Methods: A mixed-methods approach was used to evaluate the program, including a qualitative focus group with clerkship preceptors and ongoing quantitative student evaluations.

Results: Preceptors reported that students related to the film in highly personal ways, often recounting experiences within their own families, and gained a greater appreciation of caregivers. Three years of student evaluations $(n=403)$ were used to validate preceptor comments. Students agreed that the program helped them establish a comfortable relationship with caregivers, increased their awareness of caregiver challenges and rewards, and provided valuable insights into caregiver experiences.

Conclusions: Film depicting compelling narratives of caregiver journeys, coupled with guided discussion, is a valuable strategy for increasing student awareness of the important role of caregivers.

The demand for family caregiving is escalating with the increasing prevalence of chronic disease, aging of our population, and long-term care trends that promote home care. ${ }^{1-6}$ In 2014 , close to 40 million Americans provided unpaid care to an adult. ${ }^{7}$ Clinicians have a responsibility to identify the burdens on caregivers and to facilitate individualized interventions. ${ }^{8}$ Assessing caregiver needs is central to person- and family-centered care, ${ }^{9}$ yet good communication between caregivers and health care providers is rarely established. ${ }^{10}$ The Institute of Medicine (IOM) report Crossing the Quality Chasm states that family caregivers should be involved in decision-making, feel welcomed and comfortable in the care delivery setting, and be recognized for their unique needs and contributions. ${ }^{11}$ Medical students encounter caregivers on clinical rotations, yet receive limited training on how to communicate with them. ${ }^{12}$

Film is commonly used in medical education to elicit deeper understanding of patients' experiences, ${ }^{13,14}$ and can be used to highlight caregiving experiences. Because there has been no past research about the impact of film in medical education to increase awareness of caregivers, our objective was to assess the value of the film, No 
Roadmap: Caregiver Journeys, coupled with guided discussion, as a means of sensitizing third-year medical students to caregiver issues. We define sensitizing as making students more aware of the experiences of caregivers, a first step toward empathizing with caregivers.

The 20-minute film produced by Northeast Ohio Medical University (NEOMED) and Summa Health was crafted to generate discussion and evoke emotions in response to four family narratives of their caregiving journeys. The film is included in a compendium of web-based educational tools developed for a larger project, Building Caregiver Partnerships Through Interdisciplinary Education, funded by the Arthur Vining Davis Foundations. ${ }^{15,16}$ The website includes a link to the film, discussion guides, case scenarios, clinical experiences, and simulated team meetings.

\section{Methods}

The film and guided discussion were integrated into the family medicine clerkship curricula at nine partner sites and aligned with an existing hospice experience. During the hospice experience, students are placed at a communitybased hospice agency and paired with a patient for three visits, including preparatory and debriefing sessions for each visit (Table 1). A mixed-methods study design was used to evaluate the program on two fronts: (1) qualitative research via a focus group of clerkship preceptors, and (2) quantitative questions asking specifically about the caregiver film and discussion added to student evaluations of their rotation.

\section{Data Collection}

After a year of implementation (summer of 2015), all hospice preceptors were invited to participate in a focus group about the caregiver film. Nine of the 15 hospice preceptors invited participated for a response rate of $60 \%$ with those not participating citing schedule conflicts. The nine participants were a good representation of the 15 possible. Breakfast was provided to participants as an incentive. Questions addressed the best time to introduce the film so that students would better understand the role of caregivers, the students' engagement during the session, the usefulness of the film for sensitizing students or increasing their awareness of caregiver experiences, use of the discussion questions, and the effect on student interactions with caregivers during their hospice visits. In addition to the preceptor focus group, three questions were added to an existing student evaluation for the family medicine clerkship between 2014 and 2017 to measure the awareness or sensitivity of students to caregiver issues. Of the 427 possible students, 403 (94\%) completed a student evaluation.

\section{Data Analysis}

The audio recording from the preceptor focus group was transcribed and a content analysis was conducted. Authors K.B. and B.P. independently coded the data, met to compare codes, and reached consensus on main themes. Authors M.S. and M.B. reviewed the transcript and themes to validate the earlier coding. Descriptive statistics were used to describe the quantitative data from 403 student evaluations. NEOMED Institutional Review Board classified this project as program evaluation, and not human subjects research. However, focus group participants signed forms granting permission for audio recording.

\section{Results}

\section{Clerkship Preceptor Focus Group Results}

Five themes emerged from the focus group (see Table 2 for supporting quotes). First, many students identified with the families in the film and often had an emotional response, thinking of their own family. Second, students were surprised to learn how important the family was in the patient's care and recognized the importance of the role after viewing the film. Third, most preceptors waited until the second visit to show the film, giving the students more time to acclimate before discussing the role of family. Fourth, preceptors also stated the usefulness of the educational activity within the family medicine rotation. Lastly, the preceptors indicated that the discussion guide was helpful when they first started using the film, but later used it as just a backup.

\section{Medical Student Evaluations}


Most students ( $n=231,54.9 \%)$ reported that they spoke with a caregiver during their home visit. All three questions on the student evaluations received positive responses (Table 3 ). For each question, $95 \%$ or more of the students agreed or strongly agreed that the film was helpful in understanding caregiver challenges, in understanding caregiver experiences with end-of-life care, and in establishing relationships with caregivers.

\section{Discussion}

By depicting personal narratives of family caregivers, the film and guided discussion can be valuable tools for sensitizing medical students to issues of family caregiving. Film conveys the perspectives of caregivers in a compelling way that is difficult to gain in the constraints of busy clinical rotations. As families relay both challenges and rewards of caregiving, students learn about caregiving roles throughout the patient's illness trajectory. Family relationships, personal circumstances, household situations, rigors of care, and relationships with professional providers are discussed. Students reported that the film and discussion gave them an appreciation for caregiver challenges and experiences. They also recognized the need to build relationships with caregivers and help support them in their vital roles.

Rich in content, yet only 20 minutes in length, the film No Roadmap: Caregiver Journeys was designed to evoke emotion and generate discussion. Through guided discussion students can relate the film's narratives to their personal lives as well their clinical encounters. Because of the frank discussion of death, faculty should anticipate students becoming emotional during the viewing, especially if they are reminded of the loss of a family member or patient. Discussion of the film should, therefore, take place in a safe space, where students are comfortable expressing their feelings. Some students may need additional mentoring outside of the discussion group to process end-of-life issues.

Our program evaluation was limited in that we only conducted one focus group with clerkship preceptors in which only $60 \%$ of preceptors were able to attend. Preceptors who attended may have been more positive about the program than those absent. However, we felt the nine participants were representative of the 15 possible. We did not survey those who did not attend but did hear back informally that they felt the film was useful and were still using it. In addition, results from our student evaluations supported statements made by preceptors during the focus group. While we cannot prove that the film and discussion were effective in sensitizing students to the role of caregivers since we had no comparison group, the faculty comments and student evaluations both indicate that students gained insight into these roles. Another limitation is the lack of a formal measure of sensitization. We wanted students to be more aware of the role of caregivers, but did not use a validated scale measuring sensitization. In future research it may be useful to have students write reflective essays specifically addressing their interactions with caregivers, as well as with patients.

In conclusion, film can be an adaptable tool that can be easily integrated into clinical and classroom settings. We found it advantageous to embed the film and guided discussion into a well-established required hospice experience in the family medicine clerkship, but have also used the film with residents and other health profession students. The faculty preceptors embraced the film as it enriched the students' experiences. While preceptors found the discussion guide helpful to begin conversations, they found it most effective to tailor the discussions to the students' experiences. The film and resources can be accessed on the Portal of Geriatrics Education (POGOe) and NEOMED's websites. ${ }^{15,16}$

\section{Tables and Figures}


Table 1: Description of the Hospice Educational Experience and Where the Film Was Integrated Into the Experience

\begin{tabular}{|c|c|}
\hline Objectives & Activities \\
\hline $\begin{array}{l}\text { Session \#1 } \\
\text { Identify the services and benefits that hospice } \\
\text { provides the patient and family. } \\
\text { Become acquainted with a hospice patient and his/ } \\
\text { her caregiver. }\end{array}$ & $\begin{array}{l}\text { Preparatory: Hospice agency orientation. Preparation and expectations for } \\
\text { home visit. } \\
\text { Accompany a hospice nurse, social worker, or chaplain to the } \\
\text { patient's home: Listen to patient's and caregiver's narratives. } \\
\text { Debrief: Discuss visit and personal experiences with death and dying. }\end{array}$ \\
\hline $\begin{array}{l}\text { Session \#2 } \\
\text { Discuss the caregiving experience from a family } \\
\text { perspective. } \\
\text { Describe the interdisciplinary hospice team approach } \\
\text { to care of the patient and family. } \\
\text { Describe the role the family caregiver has played } \\
\text { throughout the patient's illness. }\end{array}$ & $\begin{array}{l}\text { Preparatory: View } 20 \text {-minute caregiver film and discuss. Attend a hospice } \\
\text { team meeting. Discuss expectations for home visit. } \\
\text { Unaccompanied visit to patient's home: Discuss what is most important } \\
\text { to the patient at this point in life; the challenges and rewards for the } \\
\text { caregiver; and what hospice has meant to them. } \\
\text { Debrief: Discuss visit and write a reflective essay on the experience with } \\
\text { the hospice patient. }\end{array}$ \\
\hline $\begin{array}{l}\text { Session \#3 } \\
\text { Discuss the importance of self-care and self- } \\
\text { awareness in caring for patients with terminal illness } \\
\text { and their caregivers. }\end{array}$ & $\begin{array}{l}\text { Preparatory: Discuss how to gain closure with the patient and caregiver } \\
\text { and how to take a spiritual history. } \\
\text { Unaccompanied visit to patient's home: Discuss patient's and } \\
\text { caregiver's cultural and spiritual beliefs and how they have influenced their } \\
\text { care decisions. Say goodbye. } \\
\text { Debrief: Discuss the meaning of the experience and how it will influence } \\
\text { student's future care of terminally patients and their caregivers. }\end{array}$ \\
\hline
\end{tabular}


Table 2: Thematic Analysis With Supporting Quotes From the Clerkship Preceptors' Focus Group

\begin{tabular}{|c|c|}
\hline Theme & Supporting Quotes \\
\hline $\begin{array}{l}\text { Identifying with } \\
\text { families }\end{array}$ & $\begin{array}{l}\text { Our last group was moved to tears... usually they can identify with someone in their family. } \\
\text { Their own family, yeah... Grandpa's dying or...other members they've taken care of somebody in the family } \\
\text { for many years. I think they can really identify with it. }\end{array}$ \\
\hline $\begin{array}{l}\text { Recognition } \\
\text { and surprise } \\
\text { about needs } \\
\text { and concerns of } \\
\text { caregivers }\end{array}$ & $\begin{array}{l}\text { Students l've talked to, if it doesn't remind them of someone in their family, it's kind of eye-opening for them to } \\
\text { see, to realize all that is involved in caregiving. } \\
\text { I think it's very believable and that's kind of the feedback we've got [from students]. It doesn't seem scripted. I } \\
\text { think they buy into real quickly that there's value to this. It's real. } \\
\text { I think it gives them an opportunity to see those distinct different scenarios that happen. } \\
\text { The thing that l've noticed is that the more positive comments we've had from the students, I think, reflect } \\
\text { a kind of a surprise...before...they focus on the family as the difficult family... family seems to get in the } \\
\text { way of them and what they need to do on their clinical rotations. So now they really get to see it through the } \\
\text { caregiver's eyes, through the family's eyes... and it's like... you never really paid that much attention to what } \\
\text { they really did, how important they are. So that's been a pretty constant feedback we've had at the debriefing. } \\
\text { It surprises them. }\end{array}$ \\
\hline Readiness for film & $\begin{array}{l}\text { So I think it worked pretty good for the second [hospice] visit. I think all the butterflies get worked out the first } \\
\text { visit and they're just trying to get used to what is going on. There's a little more of a comfort level, the family } \\
\text { knows them the second time around a little bit. So I think they are more able to pay attention to the family part } \\
\text { of it. } \\
\text { They usually see it on the second visit. And frankly, you know, I think that's fine. You know, they can bring } \\
\text { their own... predispositions and then have that illuminated by a more sophisticated vision and see what kind } \\
\text { of merger they can make of this. }\end{array}$ \\
\hline $\begin{array}{l}\text { Timing within } \\
\text { family medicine } \\
\text { rotation }\end{array}$ & $\begin{array}{l}\text { Maybe l'm biased for being family medicine but I think it really fits well for the family medicine clerkship } \\
\text { because I think when they leave the hospice part of it they're surrounded by a milieu where everybody } \\
\text { is paying attention to them-the family and the caregivers. Then they go to clinic and they see the whole } \\
\text { spectrum of family and the continuity of care thing. So I think it is important that it's provided in a setting that } \\
\text { once they leave that hospice mourning that if something pops up they can find a preceptor or physician or } \\
\text { staff that is kind of really focused on the family, also. To support all those questions that come up later on as } \\
\text { they are trying to process it. }\end{array}$ \\
\hline $\begin{array}{l}\text { Discussion guide } \\
\text { helpful in beginning }\end{array}$ & $\begin{array}{l}\text { It's a good resource to fall back on... if students aren't bringing anything up on their own. Each group is so } \\
\text { different sometimes it goes directions you wouldn't expect based upon that particular family, that particular } \\
\text { student and... then it triggers something else... it covers the bases pretty well. } \\
\text { I probably used it maybe the first or second time doing it. But I really kind of pull questions out based on the } \\
\text { [stories in the film].... and sometimes it's based on... situations [students] are going through. }\end{array}$ \\
\hline
\end{tabular}

Table 3: Student Evaluation Questions From Fall 2014 Through Spring 2017

\begin{tabular}{|c|c|c|c|c|}
\hline Question & $\begin{array}{l}\text { Strongly } \\
\text { Agree }\end{array}$ & Agree & Disagree & $\begin{array}{l}\text { Strongly } \\
\text { Disagree }\end{array}$ \\
\hline $\begin{array}{l}\text { The caregiver video and discussion helped prepare me } \\
\text { to understand the challenges and rewards of caregiving. }\end{array}$ & $\begin{array}{c}195 \\
(48.4 \%)\end{array}$ & $\begin{array}{c}194 \\
(48.1 \%)\end{array}$ & $\begin{array}{c}13 \\
(3.2 \%)\end{array}$ & $\begin{array}{c}1 \\
(0.3 \%)\end{array}$ \\
\hline $\begin{array}{l}\text { From watching the video and visiting the patient, I } \\
\text { gained insight into the caregiver's experience with end- } \\
\text { of-life care. }\end{array}$ & $\begin{array}{c}187 \\
(55.3 \%)\end{array}$ & $\begin{array}{c}135 \\
(39.9 \%)\end{array}$ & $\begin{array}{c}14 \\
(4.1 \%)\end{array}$ & $(0.6 \%)$ \\
\hline $\begin{array}{l}\text { From watching the video and visiting the patient, I } \\
\text { established a comfortable relationship with the patient's } \\
\text { caregiver. }\end{array}$ & $\begin{array}{c}186 \\
(57.9 \%)\end{array}$ & $\begin{array}{c}122 \\
(38.0 \%)\end{array}$ & $\begin{array}{c}11 \\
(3.4 \%)\end{array}$ & $(0.6 \%)$ \\
\hline
\end{tabular}

\section{Acknowledgments}

This project is dedicated to all the remarkable families who provide support and care to their loved ones. We acknowledge the interdisciplinary steering committee members from Summa Health and Northeast Ohio Medical University whose expertise and passion made this project possible.

Financial Support: Funding was provided by the Arthur Vining Davis Foundations. 


\section{Corresponding Author}

Kristin R. Baughman, $\mathrm{PhD}$

Department of Family and Community Medicine, Northeast Ohio Medical University, 4209 State Route 44, PO Box 95, Rootstown, OH, 44272. 330-325-6161. Fax: 330-325-5907.

kbaughma@neomed.edu

\section{Author Affiliations}

Barbara Palmisano, MA - Department of Family and Community Medicine, Northeast Ohio Medical University, Rootstown, $\mathrm{OH}$

Margaret Sanders, MA, LSW - Department of Family and Community Medicine, Northeast Ohio Medical University, Rootstown, $\mathrm{OH}$

Michael Blackie, PhD - Department of Medical Education, University of Illinois at Chicago, College of Medicine, Chicago, IL

David Sperling, MD - Department of Family and Community Medicine, Northeast Ohio Medical University, Rootstown, $\mathrm{OH}$

Erin Scott, MD - Division of Palliative Care and Geriatrics, Massachusetts General Hospital, Boston, MA Steven Radwany, MD - Division of Palliative Medicine, Department of Internal Medicine, The Ohio State University Wexner Medical Center, Columbus, $\mathrm{OH}$

Jennifer Drost, DO, MPH - Summa Health, Akron, $\mathrm{OH}$

\section{References}

1. IOM (Institute of Medicine). Dying in America: Improving Quality and Honoring Individual Preferences Near the End of Life. Washington, DC: The National Academies Press; 2014.

2. Family Caregiver Alliance. Caregiver Assessment: Principles, Guidelines and Strategies for Change. Report from a National Consensus Development Conference (Vol. I). San Francisco: Family Caregiver Alliance; 2006.

3. Family Caregiver Alliance. National Center on Caregiving National Policy Statement. https://www.caregiver.org/national-policy-statement. Accessed August 17, 2017.

4. Feinberg L; Institute of Medicine, Committee on Transforming End-of-Life Care. Policies and Family Caregiving. Washington, DC: National Academies Press; 2013.

5. IOM (Institute of Medicine). Retooling for an aging America: Building the health care workforce. National Academies Press: Washington, DC; 2008.

6. Evercare by United Healthcare and National Alliance for Caregiving. The Evercare survey of the economic downturn and its impact on family caregiving. 2009. http://www.caregiving.org /data/EVC_Caregivers_Economy_Report\%20FINAL_4-28-09.pdf. Accessed August 14, 2017.

7. National Alliance for Caregiving. Caregiving in the US 2015. http://www.caregiving.org/caregiving2015/. Accessed August 14, 2017.

8. Burden C and Quite NRS. A practical guide to caring for caregivers. Am Fam Physician. 2000;62(12):2613-20.

9. Feinberg L, Reinhard SC, Houser A, Choulaet R. Valuing the Invaluable: 2011 Update. The Growing Contributions and Costs of Family Caregiving. Washington DC: AARP Pubic Policy Institute; 2011.

10. Adelman RD, Tmanova LL, Delgado D, Dion S, Lachs MS. Caregiver burden: a clinical review. JAMA. 2014;311(10):1052-1060. https://doi.org/10.1001/jama.2014.304

11. IOM (Institute of Medicine). Crossing the Quality Chasm: A New Health System for the $21^{\text {st }}$ Century. Washington, DC: National Academies Press; 2000.

12. Garner KK, Henager AA, Kirchner JE, Sullivan $\mathrm{DH}$. The elephant in the room: facilitating communication at the end of life. Fam Med. 2011;43(4):277-278.

13. Law M, Kwong W, Friesen F, Veinot P, Ng SL. The current landscape of television and movies in medical education. Perspect Med Educ. 2015;4(5):218-224. https://doi.org/10.1007/s40037-015-0205-9

14. Blasco PG, Moreto G. Teaching empathy through movies: reaching Learners' affective domain in medical education. Journal of Education and Learning. 2012;1(1):22-34. https://doi.org/10.5539/jel.v1n1p22 
15. Palmisano B, Sanders M, Radwany $S$, et al. Building caregiver partnerships through interprofessional education. POGOe-Portal of Geriatrics Online Education; 2016 https://pogoe.org/productid/21916. Accessed October 5, 2018.

16. Northeast Ohio Medical University Office of Palliative Care. Building Caregiver Partnerships. 2016. http://www.neomed.edu/medicine/palliativecare/building-caregiver-partnerships/. Accessed October 5, 2018.

Copyright $\odot 2019$ by the Society of Teachers of Family Medicine 